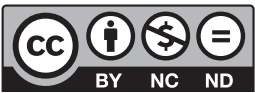

Estudos Teológicos foi licenciado com uma Licença Creative Commons Atribuição - NãoComercial - SemDerivados 3.0 Não Adaptada

http://dx.doi.org/10.22351/et.v60i1.3943

\title{
LITURGIA, RITO, CORPO E COTIDIANO: EXPERIMENTAÇÃO LABORATORIAL ${ }^{1}$
}

\author{
Liturgy, ritual, body and daily life:laboratory experimentation
}

\section{Júlio Cézar Adam² Ismael Scheffler ${ }^{3}$}

\begin{abstract}
Resumo: Este artigo pretende refletir sobre a participação da comunidade na liturgia do culto cristão, tomando como exemplo uma igreja protestante histórica e a experiência de um projeto laboratorial acadêmico: o Seminário experimental: ritualidades - pesquisas criativas. O objetivo do seminário foi refletir e buscar alternativas para aproximar liturgia e vida e, assim, possibilitar vivências comunitárias que considerem os contextos e as culturas locais. $\mathrm{O}$ artigo está estruturado em três partes, sendo as duas primeiras baseadas em revisão bibliográficas e a terceira em relato de estudo de caso. Primeiramente, será feita uma contextualização do culto na Igreja Evangélica de Confissão Luterana no Brasil (IECLB) e apresentadas as motivações para o desenvolvimento de uma experimentação laboratorial sobre o culto cristão. Na segunda parte, serão apresentados alguns referenciais teóricos importantes a respeito de culto e liturgia, relações do culto com corpo, teatro e ação, bem como conceitos de inculturação e pós-colonialidade. Por fim, será feito um relato das práticas do seminário, apontando potencialidades para o fazer litúrgico e o enriquecimento da participação da comunidade no culto cristão.
\end{abstract}

Palavras-chave: Liturgia. Corpo. Rito. IECLB. Seminário experimental.

Abstract: This article aims to reflect on the participation of the community in the liturgy of Christian worship, taking as an example a historic Protestant church and the experience of an academic laboratory project: the Experimental Seminar: rituals - creative research. The aim of the seminar was to reflect on and seek alternatives to bring liturgy and life closer together, thus enabling community experiences that take into account local contexts and cultures. The article is structured in three parts, the first two based on bibliographic reviews and the third on a case study report. First, the worship will be contextualized in the Evangelical Church of Lutheran Confession in Brazil and the motivations for the development of a laboratory experiment on Christian worship will be presented. In the second part, some important theoretical references will

1 O artigo foi recebido em 26 de março de 2020 e aprovado em 25 de abril de 2020 com base nas avaliações dos pareceristas ad hoc.

2 Doutor em Teologia. Faculdades EST. E-mail: julio3@est.edu.br

3 Doutor em Teatro. UTFPR. E-mail: ismaelcuritiba2@gmail.com 
be presented regarding worship and liturgy, the relationship between worship and body, theater and action, as well as concepts of inculturation and post coloniality. Finally, there will be an account of the practices of the seminar, pointing out the potential for liturgical activities and the enrichment of the community's participation in Christian worship.

Keywords: Liturgy. Body. Ritual. IECLB. Experimental Seminar.

\section{Introdução}

Este artigo foi primeiramente organizado para o encontro promovido pelo Calvin Institut of Christian Worship, chamado Strengthening Public Worship Practices: How Theological Disciplines Can Enrich and Deepen Congregational Life, e pretende responder a essa questão a partir do contexto brasileiro, tomando como exemplo uma igreja protestante histórica e a experiência do Seminário experimental: ritualidades - pesquisas criativas. Aproximar liturgia e vida e, assim, permitir que o culto - encontro de Deus com sua comunidade - impacte e transforme a própria vida de pessoas e comunidades que participam dos seus cultos em contextos e culturas locais é o objetivo que sustenta não só o seminário experimental, mas também esta reflexão.

O artigo está estruturado em três partes. Primeiramente, far-se-á uma contextualização do culto no Brasil, tomando como foco algumas formas de culto da Igreja Evangélica de Confissão Luterana no Brasil (IECLB) e apresentaremos os motivos que impulsionaram o desenvolvimento de um seminário prático-reflexivo sobre o culto cristão. Na segunda parte, apresentaremos alguns referenciais teóricos importantes, como a compreensão de culto e liturgia, as relações do culto com corpo, teatro e performance, bem como os conceitos de inculturação e pós-colonialidade para, finalmente, no último ponto apresentar de forma mais detalhada o desenvolvimento do Seminário experimental: ritualidades - pesquisas criativas, apontando suas potencialidades para o fazer litúrgico e o enriquecimento da participação da comunidade no culto cristão.

\section{Descrição do contexto}

O contexto brasileiro é marcado pela religião e a igreja, sendo o culto uma das principais formas de expressão dessa realidade. A primeira ação feita pelos portugueses quando invadiram o território em 1500 foi rezar uma missa. Esse episódio faz refletir sobre duas características que irão marcar o desenvolvimento cultural e religioso neste contexto. A primeira característica é o imbricamento entre religião e a conquista, legitimado pelo regime político, ou seja, culto está associado ao poder político. A segunda característica é a impossibilidade de diálogo com outras formas de cultura e religião autóctones, ou seja, o culto delimita um espaço novo, exclusivo e hegemônico no campo religioso. ${ }^{4}$ As duas características são perceptíveis até os dias de hoje.

4 Sobre o papel do culto na colonização ver BOSI, Alfredo. Dialética da Colonização. São Paulo: Cia das Letras, 1982. p. 11ss; p. 15; p. 19; p. 26ss. 
A consequência disso é que não apenas a forma oficial da fé cristã católica prevaleceu no contexto. Desde o início, formas de sincretismo religioso com as religiões indígenas e, mais tarde, com as religiões de matriz africana marcaram o cenário religioso do Brasil. Isso gerou, também, uma miscigenação cultural e religiosa sui generis e efervescente. $\mathrm{O}$ aporte protestante e o pentecostal, séculos depois, fizeram parte desse hibridismo e miscigenação religiosos, mesmo quando os negando.

$\mathrm{Na}$ atualidade, se vive no Brasil cotidianamente os efeitos dessa diversidade e efervescência religiosa. Quase podemos dizer que se vive aqui um "excesso de religião", que excede o próprio campo religioso. Religião faz parte da cultura, da sociedade, da intimidade, da política e da economia, da cultura pop, do cotidiano. Além do surgimento de novas igrejas e de movimentos religiosos, nas últimas décadas, sincretismo, mobilidade religiosa, bricolagem ou hibridismo religioso fazem parte das tendências observáveis no campo religioso. O culto é o principal âmbito para onde convergem essas tendência e, ao mesmo tempo, onde elas são formuladas e expressadas.

No contexto cristão, as denominações e tendências predominantes poderiam ser hoje assim classificadas: presença do catolicismo clássico e romanizado e do catolicismo popular, sincrético e híbrido, de um lado; e o pentecostalismo e o neopentecostalismo, com suas práticas religiosas de cunho individualizado e emocional, com apelo moral e econômico (teologia da prosperidade), do outro lado. No meio, ou na margem, estão as igrejas do protestantismo histórico, de origem missionária ou de imigração, que efetivamente entraram em cena a partir do século XIX. O projeto de culto trazido pelas igrejas protestantes e evangélicas históricas, principalmente aquele trazido pelos projetos missionários, foi marcado pelo exclusivismo confessional e em oposição ao catolicismo nas suas versões popular e romanizada.

Enquanto nas igrejas do protestantismo histórico essas tendências mais conservadoras deram, ao longo do tempo, espaço a uma postura mais aberta ao diálogo ecumênico, inter-religioso, e avançaram para um comprometimento sociopolítico, as igrejas pentecostais e neopentecostais aprofundaram o exclusivismo e a oposição.

A Igreja Evangélica de Confissão Luterana no Brasil (IECLB) faz parte do chamado protestantismo histórico e entra nesse contexto como uma igreja de imigração. Essa igreja é oriunda de um movimento migratório da Alemanha para o Brasil, a partir da primeira metade do século XIX. A liturgia que se desenvolveu na IECLB foi uma liturgia trazida na bagagem dos imigrantes, transplantada do contexto alemão para território brasileiro e, mais tarde, traduzida para o português, refletindo diferenças regionais e confessionais (luterana, reformada e unida) do contexto de origem. Diferente dos movimentos de missão, as comunidades que mais tarde deram origem à IECLB se organizaram como uma igreja étnica, germânica, significativamente voltada à manutenção da cultura e das tradições evangélico-luteranas de seus membros, sendo o culto um espaço privilegiado para tal implemento. Por mais de um século, o culto desempenhou esse papel de manutenção da cultura matriz, algo ainda perceptível em diversas comunidades.

Em especial, na década de 1970, a igreja passou por uma mudança paradigmática, na qual se buscou deliberadamente ser uma igreja brasileira, assumindo desafios sociais e se aproximando de outras denominações cristãs. O culto, porém, mesmo que 
traduzido para o português, permaneceu ainda muito próximo do culto evangélico da Alemanha de décadas atrás (liturgia prussiana e liturgia bávara). ${ }^{5}$ Apenas na década de 1980, impulsionado por movimentos de renovação litúrgica, principalmente do Conselho Mundial de Igrejas (CMI) e da Federação Luterana Mundial (FLM), se deu início a um criterioso processo de proposição de renovação da liturgia com o intuito de torná-la mais relevante, viva, ecumênica, contextual e inculturada. ${ }^{6}$

Essa reforma litúrgica se deu ao longo de vinte anos e culminou com a elaboração de um Livro de Culto (2003) ${ }^{7}$, a primeira proposta litúrgica da IECLB surgida no contexto brasileiro. ${ }^{8}$ Essa liturgia resguarda a tradição litúrgica existente na igreja cristã, a confessionalidade evangélico-luterana, mas também resgatou princípios ecumênicos (Liturgia de Lima), como a Oração Eucarística e a regularidade do Ceia no culto principal da comunidade, além de elementos inculturados, principalmente cantos litúrgicos e hinos.

Além disso, aspectos críticos tomados a partir da teologia da libertação ganharam certo destaque, como a ideia de que o culto é da comunidade, o desenvolvimento de equipes litúrgicas e a possibilidade de se moldar a liturgia. Ou seja, a comunidade assume um protagonismo litúrgico, equipes leigas são organizadas, investe-se em formação e capacitação litúrgica da comunidade, a liturgia deixa de ser algo fixo - agenda - e pode ser moldada e criada de acordo com o contexto.

O Livro de Culto propõe uma ordem litúrgica como modelo, mas adota o princípio da moldagem litúrgica, ou seja, a partir de capacitação e do conhecimento dos elementos e das partes do culto e suas funções por parte de equipes litúrgicas, a comunidade pode moldar suas liturgias. Com esse pano de fundo, o culto está assim definido:

Culto é aqui concebido como encontro que congrega Deus e um grupo de pessoas, bem como estas entre si. O sujeito do culto é Deus. Deus vem ao encontro da comunidade (Mt 18.20), e Deus de fato ordena que o culto aconteça (1Co 11.24-25: "fazei isto"). O encontro é ação de Deus. As pessoas reagem e aceitam o convite de Deus. Nesse encontro, elas ouvem sua vontade (Palavra de Deus), comungam na sua mesa (Ceia do Senhor) e realizam comunhão entre si. A Deus dirigem oração, adoração, louvor, evidenciam sua disposição de assumir o compromisso da fé, e saem do culto para testemunhar a fé e para servir ao Senhor no contexto em que estão inseridas?.

Todo esse importante desenvolvimento de renovação resultou em avanços significativos. Porém ainda hoje se percebe uma participação um tanto apática da

\footnotetext{
IECLB. Livro de Culto. São Leopoldo: Sinodal, 2003. p. 16ss.

6 Sobre a renovação litúrgica na IECLB, ver: KIRST, Nelson. Renovação litúrgica: experiências recentes na IECLB. Tear-Liturgia em Revista, São Leopoldo, n. 24, p. 5-16, dez. 2007; ADAM, Júlio C. Liturgical Formation, Liberation Theology and Latin American Culture. Studia Liturgica, v. 47, n. 1, p. 1-13, 2017. 7 IECLB, 2003.

8 Deve-se dizer que anteriormente, em 1991, o conselho de liturgia da igreja havia produzido o prontuário litúrgico Celebrações do Povo de Deus, fruto do Concílio de Três de Maio/RS. CONSELHO de liturgia da IECLB. Celebrações do Povo de Deus: Prontuário Litúrgico da IECLB. São Leopoldo: Sinodal, 1991. 9 IECLB, 2003, p. 13.
} 
comunidade na liturgia, com cultos centrados no pastor ou na pastora, liturgias muito racionais (com certo excesso de palavras e textos), preferência por liturgias importadas do hemisfério Norte e rejeição a elementos das culturas locais (como instrumentos musicais, ritmos ou determinados símbolos e vestes alternativos). Essa participação apática e conservadora é também observável em outras igrejas protestantes históricas, bem como na Igreja Católica.

O liturgista anglicano Jaci Maraschin, refletindo sobre liturgias das igrejas históricas, afirma que "nossas liturgias, em geral, são apolíneas (de Apolo e em aposição ao dinamismo de Dionísio) ${ }^{10}$ à medida que ainda se baseiam na forma logocêntrica de comunicação e se deixam governar por regras, códigos e ideias" ".1 Segundo ele, os cultos estão significativamente presos a livros de liturgia, hinários e tradições, sendo as liturgias fortemente clericais com pregações moralistas que tendem ao fundamentalismo. Destaca ainda as liturgias como sendo predominantemente masculinas. ${ }^{12}$

Ao mesmo tempo, pode-se observar essa apatia litúrgica nas igrejas históricas. Não é incomum que cultos pentecostais e neopentecostais (muitos deles contrários à tradição litúrgica das igrejas tradicionais) não apenas atraem grande número de pessoas, mas celebram de forma entusiástica, envolvendo as pessoas de forma mais integral e corporal e buscando certa inculturação de elementos cotidianos e, inclusive, religiosos. Nesse mesmo contexto, expressões da cultura popular, como o carnaval e o futebol, ou da cultura pop, como a música e o cinema, também atraem e envolvem milhares de pessoas, de diferentes gerações. Tanto nos cultos pentecostais quanto nas expressões da cultura, o uso do corpo, do movimento, da dança, descontraída e festiva, ou ainda deixando aflorar corporalmente a culpa e a dor física ou emocional, é muito visível. Cultos mais dinâmicos e de expressão pessoal, mais brasileiros, mais inculturados, mesmo tendo sido idealizados pelos movimentos de renovação litúrgica da IECLB e de outras igrejas, se efetivam em pequeno número de comunidades. A relação entre culto e vida parece às vezes algo distante.

\section{Análise teórica e teológica}

\section{Culto e liturgia}

A busca por aproximar vida e culto parte de uma compreensão do próprio culto e da liturgia. Culto é o encontro de Deus e sua comunidade e a liturgia, o conjunto de elementos e formas que viabilizam esse encontro especial. ${ }^{13}$ A liturgia emana da

\footnotetext{
${ }^{10}$ Ver NIETZSCHE, Friedrich. O Nascimento da Tragédia: ou Helenismo ou Pessimismo. São Paulo: Companhia das Letras, 2007.

${ }_{11}$ MARASCHIN, Jaci. Da leveza e da beleza: liturgia e pós-modernidade. São Paulo: ASTE, 2010. p. 25.

12 MARASCHIN, 2010, p. 28.

13 KIRST, Nelson. Liturgia. In: SCHNEIDER-HARPPRECHT, Christoph (Org.). Teologia prática no contexto da América Latina. São Leopoldo: Sinodal; ASTE, 1998. p. 119-141.
} 
tradição bíblica e eclesiástica e encarna-se na cultura e na vida da comunidade, numa dinâmica permanente de criação por meio da palavra de Deus. ${ }^{14}$

Essa dinâmica do culto cristão é ação representativa (darstellendes Handeln ${ }^{15}$ ) de todo o Evangelho, de forma que no culto circula o Evangelho em forma de ação representativo-simbólica, como comunicação pública da experiência cristã. Ou seja, o culto cristão recapitula, atualiza e divulga toda a história de Deus com seu povo, história registrada na Bíblia e na própria tradição do povo de Deus, a igreja. ${ }^{16}$

A função principal e central do culto cristão é despertar e alimentar a fé cristã, como aponta Heimbrock: "Culto cristão não tem, em primeiro ou último lugar, nenhuma pretensão específica, mas quer ser 'agir representador', quer dar expressão à alegria do ser humano pela libertação de Deus, expressão total, se possível"17. Toda celebração litúrgica significa, portanto, um abrir-se e um deixar-se surpreender por algo maior que qualquer ação humana, independentemente de quão justa, digna e do nosso dever essa ação possa ser. Por isso toda forma de objetivação para os próprios propósitos, por mais nobre e necessária que seja, viola a essência do culto cristão. Isso, porém, não significa dizer que o culto seja celebrado num vácuo cultural, social e corporal. O culto só é possível pela sua dimensão humana corporal e cultural, a qual se encontra sempre presente na essência da própria liturgia, como serviço encarnatório de Deus para dentro da realidade concreta, por meio da vida, de histórias, corpos e sentidos de pessoas concretas.

A definição do teólogo luterano Peter Brunner ${ }^{18}$, valendo-se do termo alemão Gottesdienst, corrobora a ideia apresentada acima. O termo Gottesdienst permite, ao mesmo tempo, dizer que o culto é serviço de Deus à comunidade e serviço da comunidade perante Deus. Nessa compreensão, culto é sempre uma reação àquilo que Deus primeiro fez e faz em Jesus Cristo, o culto pleno. O serviço da comunidade perante Deus é o serviço de amor ao próximo, por meio da fé, fé despertada e mantida por Deus. Nos dois movimentos é sempre Deus quem age ${ }^{19} \mathrm{O}$ que o coração é para o corpo, o culto é para igreja: a partir dele e de volta para ele circula todo o agir da igreja. ${ }^{20}$

Essa ação de Deus no culto sempre irá provocar algo nas pessoas, na comunidade e no mundo, algo que vai além da sua função primeira, como ação e serviço de Deus que cria e mantém a fé, o que Rössler chama de "efeitos colaterais" 21 . A partir desses efeitos colaterais do culto, Peter Cornehl ${ }^{22}$ fala de quatro funções do culto cris-

\footnotetext{
14 WAINWRIGHT, Geoffrey. Fundamentação sistemático-teológica. In: SCHMIDT-LAUBER, H.-C. et al. (Orgs.). Manual de Ciência Litúrgica. São Leopoldo: EST; Sinodal, 2011. v. 1, p. 112ss.

15 SCHLEIERMACHER, Friedrich. Die Praktische Theologie nach den Grundsätzen der Evangelischen Kirche. Berlin: O. Reimer, 1850 (1983). p. 70.

16 ALLMEN, J. J. von. O culto cristão: teologia e prática. 2. ed. São Paulo: ASTE, 2006. p. 21.

17 HEIMBROCK, H.-G. Gottesdienst: Spielraum des Lebens. Sozial- und Kulturwissenschaftliche Analysen zum Ritual in praktisch-theologischem Interesse. Kampen: Kok; Weinheim: Deutscher Studien Verlag, 1993. p. 9.

18 WHITE, James F. Introdução ao Culto Cristão. São Leopoldo: Sinodal, 1997. p. 15s.

19 WHITE, 1998, p. 15.

20 ALLMEN, 2006.

${ }^{21}$ RÖSSLER, Dietrich. Die Vernunft der Religion. München: Piper, 1976.

22 CORNEHL, Peter. Theorie des Gottesdienst. Theologie Quartalsschrift, n. 159, p. 178-195, 1979.
} 
tão. O culto possibilita mais do que apenas informação, mas também expressão por meio do rito, dos símbolos e da esperança. Além disso, o culto é lugar de orientação por meio da ação representativa do Evangelho. Culto é também espaço de afirmação da fé que move a comunidade e, por fim, o culto é um momento de integração, onde a comunidade se constitui como tal.

Ernst Lange ${ }^{23}$ defende a existência de outras quatro funções que o culto causa na pessoa e na comunidade que o celebra: identidade, distância, celebração e festa. $\mathrm{O}$ culto cria identidade nas pessoas que o celebram, funcionando como um espelho, através do qual a comunidade se vê e se reconhece. Essa identidade não é uma simples identidade cultural ou social, mas uma identidade que vem de fora, dada pelo próprio Deus por meio de Jesus Cristo. É através de Cristo e por meio dele que a comunidade se reconhece. O culto cristão cria também distância. Mesmo que o culto esteja imbricado com a realidade e o contexto, ele é um momento consagrado, que cria um espaço de distanciamento, de avaliação do contexto e de si próprio, de sua identidade desfigurada, de contato com o alternativo, o utópico, o que Lange nomeia como um contramundo, como uma força de resistência, oposição e subversão da ordem. O culto se organiza em torno da celebração. O culto cria um espaço para celebrar a vida, a existência em sua humanidade, no seu significado mais autêntico e profundo que é encontrado em Jesus Cristo, o motivo da festa. Por último, o culto cristão é festa, jogo lúdico, brincadeira diante de Deus, possibilidade de inverter subversivamente a realidade, sua crueza e crueldade.

Culto é uma ação representativa do Evangelho para dentro e a partir da vida de sua comunidade. Sua função é despertar e manter a fé da comunidade que o celebra por meio da Palavra que reverbera na vida do cotidiano local. Concretamente isso se dá, pelo menos, por meio de expressão, orientação, afirmação e integração, propiciando identidade, distância, celebração e festa. Por envolver a vida de pessoas e culturas concretas, o teatro e a performance têm imensa contribuição a oferecer, na medida em que permitem entender o papel da corporeidade, da intimidade, do movimento, da expressão, do lúdico e do drama no culto. ${ }^{24}$ Por isso pesquisas e estudos nessa inter-relação têm sido de grande importância para esse experimento.

\section{Inculturação e pós-colonialidade}

Como relatado no primeiro ponto deste artigo, o culto na América Latina e no Brasil caracteriza-se ou como parte do programa de colonização ibérica ou como manutenção de identidades étnicas de grupos minoritários, como no caso dos imigrantes alemães e da IECLB até meados do século passado. Em ambos os casos, o culto, com seu ordo litúrgico, hinos, calendário e espaço litúrgicos, vestes etc., foi transplantado

${ }^{23}$ LANGE, Ernst. Predigen als Beruf: Aufsätze zu Homiletik, Liturgie und Pfarramt. 2. Aufl. München: Kaiser, 1987. p. 85-89.

24 "Der christliche Gottesdienst ist zwar kein Kultdrama oder Theater, doch immer suchte und fand er seine eigene Form auch in Transformation und Abgrenzung von beiden." SCHILSON, Arno; HAKE, Joachim (Orgs.). Drama “Gottesdienst”: zwischen Inszenierung und Kult. Stuttgart: Kohlhammer, 1998. p. 9. 
para o hemisfério Sul. As culturas locais e a vida cotidiana, muitas vezes, foram vistas como algo que não penetrava nas agendas litúrgicas, restringindo-se, por vezes, à tradução dos textos para o idioma local. Mesmo a teologia da libertação, que se desenvolveu como uma teologia contextual e estreitamente relacionada à realidade sociopolítica local, principalmente na área bíblica, sistemática e eclesiológica, pouco se ocupou com questões litúrgicas, como se o culto não tivesse relação com o contexto. ${ }^{25}$

Em grande medida, impulsiondas pela reforma litúrgica do Concílio Vaticano II e pelo Conselho Mundial de Igrejas, a partir das décadas de 80 e 90, as igrejas protestantes brasileiras iniciam um processo de renovação litúrgica, na qual a inculturação teve forte impacto. No caso da IECLB, também os estudos sobre culto e cultura da Federação Luterana Mundial ${ }^{26}$ tiveram grande relevância no processo de renovação litúrgica. Aos poucos, tomou-se consciência do impacto negativo da "cultura do outro", da cultura do norte, como cultura padrão e seu poder de domínio sobre as culturas locais e autóctones, indígena, africana e popular. A questão não era simplesmente inculturar: era preciso perguntar como inculturar, o que inculturar, para que e para quem inculturar. ${ }^{27}$

Inculturação é um processo por meio do qual a liturgia da igreja se relaciona e interage com a cultura local, permitindo que o Evangelho se encarne na cultura, na vida, na história da comunidade litúrgica de um tempo e um local. Este é o objetivo imediato da inculturação: permitir que a comunidade tenha um culto que reflita sua cultura e possa, assim, ouvir e vivenciar adequadamente o Evangelho. O que se incultura, obviamente, é o Evangelho de Jesus Cristo. Os luteranos creem que o Evangelho vem para a igreja através de elementos concretos: a palavra de Deus e os sacramentos. Esses elementos, herdados de um amplo e longo processo de contextualização, convertem-se em uma "forma" ou "ordem" (ordo): Palavra, Batismo e Eucaristia. Mesmo que o ordo seja resultado de um processo encarnatório, um processo de inculturação, é ele mesmo que sempre de novo se incultura. Ou seja, inculturação parte desse ordo já estabelecido ${ }^{28}$, mas não se encerra nele mesmo.

Ao lado do exercício de inculturação, um novo conceito ganhou atenção na última década: pós-colonialidade ou decolonialidade. Mais que um conceito, a pós-colonialidade ou decolonialidade é uma nova maneira de perceber a realidade local (e global) a partir de suas diferenças, sutilezas, diversidades, fragmentaridades, alteridades, rompimentos e alternativas sociais, culturais, corporais, sexuais, políticas e religiosas, e não apenas do estabelecido e do padronizado.

${ }^{25}$ BUYST, Ione. Teologia e liturgia na perspectiva da América Latina. In: FAVRETO, C.; RAMPON, Ivanir A. (Orgs). Eu sou o que sou. Passo Fundo: Berthier, 2008. p. 38-76. Destacam-se, como excessão, as liturgias que foram por outra via, como as liturgias da América Central, a Missa Crioula Argentina e a Missa dos Quilombos e da Terra Sem Males, bem como as Romarias da Terra, no Brasil.

${ }^{26}$ LATHROP, Gordon. The shape of the liturgy. In: STAUFFER, S. Anita (Ed.). Christian worship: unity in cultural diversity. Geneva: LWF, 1996. p. 67-75; CHUPUNGCO, Anscar J. Two Methods of Liturgical Inculturation. In: STAUFFER (Ed.), 1996, p. 77-94, nas versões em espanhol.

27 ADAM, Júlio C. Worship with a Brazilian Face. In: VASCONCELOS WILKEY, Gláucia. Worship and Culture. Grand Rapids; Cambridge: Eerdmans, 2014. p. 239ss.

${ }^{28}$ LATHROP, 1996, p. 67. 
[...] Falar em pós-colonialidade significa questionar e desconstruir a dinâmica de identificação à qual as forças coloniais aspiram, expondo suas próprias fraquezas através das heterogeneidades inscritas em tal Sujeito, com o objetivo de tornar visíveis as bifurcações intrínsecas que caracterizam o contexto global, que permitem sua constante maleabilidade, transformação e abertura para novas formas de construção sociocultural. ${ }^{29}$

Dessa forma, a pós-colonialidade intensifica o olhar para a cultura, o cotidiano, o corpo, acentuando em especial a diferença, aqueles aspectos que não se enquadram nos padrões homogêneos dos sistemas colonizadores e que por isso são vistos como débeis, frágeis e vulneráveis. Esse novo olhar terá impacto sobre a inculturação da liturgia, buscando não só o diálogo com as especifidades e nuanças das culturas locais, mas pensando a liturgia como espaço de transformação sociopolítica, algo que Claudio Carvalhaes chama de um liturgical turn.

A virada litúrgica continua com a tradicionação, desafiando interpretações, questionando não apenas o pensamento litúrgico e as práticas da igreja, mas também suas muitas ordens, símbolos, formas de criação litúrgica, compreensão de corpos e sexualidades, vocabulários, usos da Bíblia, recursos litúrgicos, formas de acesso às coisas sagradas, relações com a economia e outros campos e assim por diante. (tradução nossa) ${ }^{30}$

\section{Cotidiano, movimento, corpo e rito}

A liturgia que temos no ordo nasceu da vida, da vivência prática, como expressão corporal e simbólica da experiência vivida, como o banho que limpa e refrigera o corpo no Batismo, a refeição à mesa, o encontro das pessoas para ouvir, ver, cheirar, degustar, tocar e sentir na Eucaristia. Dessa forma, os ritos estão relacionados à vida prática e servem para resolver dramas sociais e individuais (Victor Turner). Com o passar do tempo, as práticas rituais foram sendo cristalizadas, formatadas, de modo que hoje, muitas vezes, os ritos litúrgicos tornam-se algo estranho à vida, distantes da vida concreta da comunidade celebrante.

29 “'...] hablar de poscolonialidad significa cuestionar y deconstruir las dinámicas de identificación que ambicionan las fuerzas coloniales, exponiendo sus proprias debilidades a través de las heterogeneidades inscriptas en tal Sujeto, con la intención de visibilizar las intrínsecas bifurcaciones que cartacterizan el contexto global, las cuales permiten su constante maleabilidad, transformación y apertura hacia nuevas formas de construción sociocultural.” PANOTTO, Nicolás. Religión, Política y Poscolonialidad en América Latina: hacia una teología posfundacional de lo público. Madrid; Buenos Aires: Miño y Dávila, 2016. p. 34s.

30 "The liturgical turn continues with the traditioning, challenging interpretations, questioning not only liturgical thinking and church practices, but also its many orders, symbols, forms of liturgical creation, understanding of bodies and sexualities, vocabularies, uses of the Bible, liturgical resources, forms of access to holy things, relations to economics and other fields, and so on." CARVALHAES, Cláudio (Ed.). Liturgy in Postcolonial Perspectives: Only One is Holy. New York: Palgrave Macmillan, 2015. p. 8. Para a liturgia são também importantes os trabalhos de: BARROS, Marcelo. Celebrar Deus da vida: tradição litúrgica e inculturação. São Paulo: Loyola, 1992; JAGESSAR, Michael; BURNS, Stephen. Christian Worship: Postcolonial Perspectives. London: Cross Cultural Theologies, 2011; LARTEY, Emmanuel. Postcolonializing God: an African Practical Theology. London: SCM, 2013. 
Na realidade litúrgica de muitas igrejas brasileiras, a dimensão do corpo é uma dimensão esquecida, principalmente no âmbito protestante. ${ }^{31}$ Por vezes, parece que vamos ao culto apenas com a razão e a cabeça, inclusive no Brasil, onde a cultura encontra no corpo, no movimento, nas emoções um importante meio de expressão. Aldo Vannucchi, pesquisador católico, alerta para a necessidade de se considerar o corpo e a expressão simbólica e ritual na liturgia do culto:

Não somos puros espíritos. Pensamos, amamos, cremos, oramos, salvamo-nos também com nosso corpo. Melhor: somos também corpo. Daí, se a Liturgia, por hipótese impossível, pretendesse menosprezar nossa corporeidade existencial, não nos diria nada, nem seria momento de encontro, por Jesus Cristo, com o Pai, na unidade do Espírito Santo, porque o Cristo real é o Verbo feito carne, nascido de Maria, "na condição de servo, feito semelhante aos homens" ${ }^{132}$.

Falar do corpo no culto não é algo genérico e abstrato, mas tem relação direta com a vida vivida no corpo, como espaço do prazer e da dor, dos desejos e das misérias, das fomes, sedes e dos medos, do cansaço e da alegria. Falar de corpo na liturgia significa, portanto, falar da concretude, da individualidade e da diversidade da vida. O corpo e a expressão corporal, teatral e performática não são um fim em si mesmo. Essa dimensão auxilia a construir o sentido teológico-litúrgico a partir do corpo ${ }^{33}$, entendendo o culto e a liturgia como espaço onde toda a teologia da encarnação de Deus acontece como agir simbólico-representador.

Sem o realismo da encarnação, toda a Liturgia se assemelha a um teatro e teatro de mau gosto, já que, afinal aquele é atividade de frequência facultativa, ao passo que a Liturgia se proclama obrigatória. Não é à toa que, na América Latina, se ideologiza tanto, a serviço da ordem estabelecida, o próprio conceito de sacramento, reduzido a uma eficácia mágica. Se não tomamos a sério a encarnação de Deus em Jesus, evidentemente, toda a vida sacramental passará a ser apenas ritualismo e não sinal nem meio de libertação cristã. ${ }^{34}$

A crítica subjacente é a de que, após a imprensa e a modernidade, o rito acabou, em muitos casos, por se transformar na simples leitura do ordo, ou seja, a prática ritual que está na origem do ordo foi substituída pelo ordo.

No contexto brasileiro, posto em questão neste artigo, esse apego ao ordo e à tradição reflete também certa dependência colonial eurocêntrica, como já referido, implicando uma distância da vida e dos corpos concretos, um ritualismo desencarnado.

31 Neste aspecto, importante considerar a pesquisa de David Plüss sobre o culto como encenação de texto (Textinszenierung): PLÜSS, David. Gottesdienst als Textinszenierung: Perspektiven einer performativen Ästhetik des Gottesdienstes. Zürich: TVZ, 2007; ADAM, Júlio C. Liturgia e performance entre representação e comunidação: um breve relatório. Tear-Liturgia em revista, São Leopoldo, n. 40, p. 3-8, jul. 2013.

32 VANNUCCHI, Aldo. Liturgia e libertação. São Paulo: Loyola, 1982. p. 16.

33 BARONTO, Luis Eduardo Pinheiro. Laboratório Litúrgico: pela inteireza do ser na vivência ritual. São Paulo: Salesiana, 2000. p. 33.

34 VANNUCCHI, 1982, p. 40. 
O que se propõe problematizar não são meios de ajudar as pessoas a "aprender" a realizar um rito (ou encenar um conjunto de ações definidas previamente), mas apreender enquanto se participa de um rito, algo que remete à função catequética da liturgia, como dirá Buyst:

O mistério pascal de Jesus Cristo é celebrado com sinais sensíveis, que passam necessariamente pela corporeidade da pessoa humana: a reunião com os irmãos, a saudação, o abraço, orações faladas ou cantadas, a escuta da leitura das Escrituras, o canto de salmos, hinos e cânticos, a ceia, o banho com água, a unção..., andar em procissão, ajoelhar-se, sentar-se ou colocar-se em pé. Estas ações são na verdade "simbólicas" porque ligam duas realidades, duas pessoas - no caso Cristo e o seu povo ${ }^{35}$.

O culto cristão não precisa ser compreendido apenas como um evento discursivo, comunicativo e catequético, mas também um evento vivencial e representativo.

Alguns experimentos têm sido feitos partindo de elementos do teatro para repensar dinâmicas litúrgicas. Isso não significa utilizar o teatro como um recurso didático ou ilustrativo conforme a tradição medieval, da Reforma Luterana ou da Contrarreforma ${ }^{36}$ (em prática até a atualidade), de tomar o teatro como recurso didático para ditar comportamentos moralizadores, veicular conteúdos teológicos e catequizadores ou ser usado para dinamização e embelezamento do culto cristão. O teatro tem sido considerado como potencial para pensar a expressão e o enriquecimento da linguagem pessoal e coletiva.

Um exemplo foi o Laboratório Litúrgico (LL) desenvolvido por um grupo de liturgistas católicos e relatado em livro por Luiz Eduardo Pinheiro Baronto 37: "O Laboratório Litúrgico contitui-se numa técnica que assumia elementos de duas fontes básicas: a pedagogia religiosa de Hélène Lubienska de Lenval e os métodos psicodramáticos de Jacob Levy Moreno"38. O LL foir criado por um grupo de liturgistas católicos, liderado pela Dra. Ione Buyst, no final dos anos 1980, em São Paulo, como uma técnica de formação litúrgica das pessoas responsáveis pelo culto das comunidades. Ele surge para atender duas insatisfações observadas por liturgistas: a prática ritual e a maneira de ensinar liturgia. Além de liturgistas, profissionais de outras áreas, como educação física e teatro, desenvolveram a próposta do LL.

35 BUYST, Ione. Como estudar liturgia: princípios de ciência litúrgica. 2. ed. São Paulo: Paulinas, 1990. p. 22.

36 ROSENFELD, Anatol. Teatro alemão: história e estudos. I parte-esboço histórico. São Paulo: Brasiliense, 1968.

37 BARONTO, Luis Eduardo Pinheiro. Laboratório Litúrgico: pela inteireza do ser na vivência ritual. São Paulo: Salesiana, 2000.

38 BARONTO, 2000, p. 15. 


\section{O Seminário experimental: ritualidades - pesquisas criativas}

Descrição

O Seminário experimental: ritualidades - pesquisas criativas foi realizado em dois momentos diferentes na Faculdades EST, em São Leopoldo/RS, em 2016 e em $2018 .^{39}$ Foi proposto como uma atividade de pesquisa acadêmica pelo professor de liturgia e homilética, Dr. Júlio Cézar Adam, docente dessa instituição, com a colaboração do professor de liturgia Dr. Ângelo Cardita, da Universidade Laval, do Quebec, Canadá. A proposta não pretendia responder apenas às questões do culto da IECLB, mas também de outras igrejas históricas do Brasil e de outros contextos.

O Seminário Experimental tem significativa inspiração e referência da proposta do Laboratório Litúrgico, como relatado por Baronto. ${ }^{40}$

Neste sentido, foi muito importante a inclusão de um pesquisador do teatro no experimento. $\mathrm{O}$ teatro possui numerosos pontos afins à liturgia, como as práticas corporais, as vivências espaciais, o pensamento dramatúrgico, o engajamento dos atuantes, entre outros, servindo não apenas como um recurso pedagógico, mas contribuindo para reflexões teóricas e práticas sobre corpo, espaço, relação com audiência, questões sobre logocentrismo e imagem, a ação significativa de dirigentes (artistas/sacredotes) sobre um coletivo (público/comunidade), entre outros aspectos perpassados por questões pedagógicas de ensino-aprendizagem da linguagem teatral e da expressividade do ator. Relações do teatro com o sagrado têm sido tema de investigações no campo teatral $^{41}$ e religioso ${ }^{42}$.

Assim, foi convidado a integrar a pesquisa o professor de teatro Dr. Ismael Scheffler, da Universidade Tecnológica Federal do Paraná, de Curitiba/PR.

O objetivo do Seminário experimental: ritualidades - pesquisas criativas é aproximar a liturgia da vida e das culturas locais. Concretamente, ele surge como uma forma alternativa de ensino e aprendizado da liturgia por meio da vivência, da prática corporal, principalmente na formação litúrgica de estudantes de teologia em faculdades e seminários. Além disso, o Seminário tem como um dos seus objetivos buscar formas de envolver a comunidade (e não apenas ministros, ministras, e liturgistas) na celebração litúrgica.

39 Dias 16 a 18 de agosto de 2016; dias 02 a 04 de maio de 2018.

${ }^{40}$ BARONTO, Luis Eduardo Pinheiro. Laboratório Litúrgico: pela inteireza do ser na vivência ritual. São Paulo: Salesiana, 2000.

${ }^{41}$ ARTAUD, Antonin. O teatro e seu duplo. São Paulo: Martins Fontes, 1993; INNES, Christopher. Holy Theatre: Ritual and the Avant Garde. Cambridge University Press, 1981; BROOK, Peter. O teatro e seu espaço. Petrópolis: Vozes, 1970; SCHEFFLER, Ismael. Características do sagrado nas propostas teatrais de Antonin Artaud e Jerzy Grotowski. Dissertação (Mestrado em Teatro) - Universidade do Estado de Santa Catarina, Florianópolis, 2004.

42 Sobre a relação entre liturgia e teatro: FRIEDRICH, Marcus A. Liturgische Körper: der Beitrag von Schauspieltheorien und -techniken für die Pastoralästhetik. Stuttgart; Berlin; Köln: Kohlhammer, 2001; MEYER-BLANCK, Michael. Inszenierung des Evangeliums. Göttingen: Vandenhoeck \& Ruprecht, 1997. 
A partir da prática, do cotidiano, da ação, do movimento, mais do que a partir de textos e teorias, a proposta metodológica consistia em uma abordagem vivencial-reflexiva para o estudo de liturgia com a comunidade. Ela estava, portanto, apoiada em princípios fenomenológicos, vontando-se diretamente à experiência, abrindo-se os canais perceptivos, conduzindo os participantes em autoconsciência ativa a um acesso pelo corpo intencional em relação com o mundo.

Cada um dos dois encontros reuniu em torno de 15 pessoas, entre estudantes de graduação e de pós-graduação (mestrado e doutorado) em Teologia, da Faculdades EST, e participantes externos à academia (musicista, liturgista, ministros, ministras, e membros de comunidades). A maioria das pessoas participantes era luterana e um grupo menor era católico, havendo certa equidade entre homens e mulheres. Em comum, o interesse e o envolvimento com a ritualidade, a liturgia cristã, a música sacra e litúrgica, o teatro e as atividades práticas comunitárias, existindo o foco na aproximação do culto com a vida.

Tanto a experimentação de 2016 quanto a de 2018 tiveram formatos semelhantes: três tardes de trabalho em dias consecutivos. Na primeira edição, as atividades foram desenvolvidas pelos três professores e, na segunda, apenas Adam e Scheffler desenvolveram as atividades alinhadas com o modelo e objetivos desenvolvidos com Cardita em 2016.

Por meio do experimento, almeja-se criar espaço e dar tempo para o movimento do corpo, para a expressão, para sentir o corpo, experimentar como o corpo vive o cotidiano, como o corpo encontra formas e gestos para se expressar na cultura. Quando o foco foi a Eucaristia, por exemplo, o Seminário explorou, num primeiro momento, formas como as pessoas se alimentam, rememoram, agradecem, criam comunhão no cotidiano e como essas vivências podem ser expressas pelo corpo no espaço e no tempo, por meio de recursos, símbolos e metáforas, para, num segundo momento, refletir sobre como moldar a liturgia do culto. Estabelecer contato com o cotidiano e a cultura é uma tentativa de dar forma a uma liturgia inculturada, algo por vezes difícil no âmbito das igrejas históricas ainda muito influenciadas pelo paradigma colonial.

A despeito de discussões e planejamentos prévios realizados em reuniões virtuais (visto os três pesquisadores residirem em estados e países diferentes), era fundamental que o seminário fosse refletido e construído ao longo dos dias de trabalho, pois, por se tratar de uma dinâmica laboratorial, parte significativa das experimentações dependia do grupo eclético que se constituia. Embora houvesse diretrizes e objetivos, o Seminário não consistiu na aplicação de técnicas ou na apresentação de metodologias criativas aplicadas. Neste sentido, seguiu por metodologias ativas, exploratórias, com influências pedagógicas da Escola Nova, que considera fundamental que o aluno ou aluna/participante construa conhecimentos significativos tendo em conta seus saberes prévios, sua sensibilidade em relações diretas com o mundo.

Como o Laboratório Litúrgico, o Seminário Experimental se inspirou em laboratórios de teatro. Nesses, são propostas práticas de formação teatral (principalmente de atores e atrizes) que não seguem modelos tradicionais de cópia de modelos gestuais ou formas de recitar um texto, mas sim em exercícios dinâmicos, interativos, que abdicam (mesmo que temporariamente) da verbalização para dar foco ao corpo, 
protagonizadores de cenas improvisadas; atores e atrizes que são autores e autoras de suas ações e falas.

Uma diferença entre o Laboratório e o Seminário é que este não parte apenas do dado litúrgico e da observação da prática celebrativa, mas arrisca-se também partir da própria experiência cotidiana e explora a expressão corporal e o teatro em si, como meio não só da moldagem do rito litúrgico, mas também do autoconhecimento das pessoas participantes.

Outra diferença consiste nos presuspostos teatrais adotados. No Laboratório Litúrgico, o psicodrama de Moreno é referenciado como um fundamento, ao passo que no Seminário, Scheffler propôs uma abordagem alinhada com o ensino teatral de Jacques Lecoq, cuja obra principal é $O$ Corpo poético: uma pedagogia da criação teatral $^{43}$.

Em relação à proposta de David Plüss ${ }^{44}$, também há diferenças. A proposta de Plüss busca descrever e entender o culto como encenação de textos, sem restringi-lo a um evento discursivo, comunicativo e catequético, mas considerando-o também como um evento de ação, ritualístico e representativo. Já o Seminário Experimental partiu do corpo cotidiano, do movimento expressivo e da experimentação como meio para recriar e transformar o próprio culto. Ou seja, além do processo descritivo, há no Seminário ênfase no processo criativo.

Era, pois, necessário criar espaço e dar tempo para o movimento do corpo, para sentir o corpo, experimentar como o corpo vive o cotidiano, como o corpo encontra formas e gestos para se expressar. É importante reconhecer que o ser humano alienado de seu corpo (corpo domesticado e reprimido pela sociedade) está também inserido dentro de determinados contextos de tradição cristã, onde, muitas vezes, a corporeidade é menosprezada.

Assim, ao menos três aspectos precisavam ser considerados como desafio para um trabalho experimental acadêmico cristão: corpos adultos negligenciados e reprimidos ao longo de anos; o contexto acadêmico demasiado "sério" e funcionalista; a supervalorização do espírito sobre o corpo.

\section{Detalhando o seminário}

A metodologia de cada seminário previa três momentos principais: 1) experimentações práticas orientadas no sentido da pesquisa criativa; 2) relação com partes e elementos da liturgia do culto cristão; 3 ) momentos de reflexão sobre a ação, tomando como referência conhecimentos prévios, pesquisas e estudos sobre ritualidade, corporeidade, teatralidade e liturgia.

No primeiro momento, as experimentações práticas se deram a partir da disposição corporal e relacional para a ação lúdica e criativa, por meio da exploração somática da gestualidade ritual, libertando-a tanto da representação de significados

${ }^{43}$ LECOQ, Jacques. O corpo poético: uma pedagogia da criação teatral. Trad. Marcelo Gomes. São Paulo: SENAC São Paulo; SESC SP, 2010.

44 PLÜSS, 2007. 
como do funcionalismo (social ou religioso). No segundo, as partes da liturgia foram relacionadas com ações semelhantes as do cotidiano, experimentando sua execução por meio da expressão corporal. No último momento, o da reflexão, foram discutidas abordagens teóricas sobre corporeidade, ritualidade e espacialidade, e registradas por escrito, apontando seu papel e possibilidade de uso na liturgia do culto.

A seguir, são apresentados aspectos predominantes desenvolvidos nos dois Seminários:

\section{1) Experimentações práticas - tomando consciência do corpo}

No começo do Seminário e no início de cada uma das sessões de trabalho, foram propostas atividades voltadas ao corpo, ao estudo do movimento, por meio de exercícios, dinâmicas, brincadeiras, observação do próprio corpo, interação com os outros integrantes e com o espaço. O corpo próprio e do outro, o movimento, o ritmo e a percepção do espaço ganharam destaque nas dinâmicas. Exercícios foram recapitulados e aprofundados, novos exercícios foram introduzidos, de acordo com a necessidade e disponibilidade do grupo.

No momento de abertura do seminário, por exemplo, antes de se realizar apresentações por meio da fala, foi proposto estar em movimento, tomar contato consigo e estabelecer relação com outros corpos em um espaço. Esse foi um tempo especial para movimentar o corpo, percebendo-o e disponibilizando-o, algo realizado por meio de exercícios simples de espreguiçar-se e movimentar as articulações dos membros, a coluna e o quadril. Esse primeiro momento já revela a disponibilidade dos participantes, limitações físicas (problemas de coluna, ombros, limitação de alongamento) e o índice de bloqueio social (que se percebe nos comentários espontâneos realizados ao se mover e ser observado e ao observar os demais se moverem).

Dando sequência a esse primeiro momento ou no início de outras sessões, o coordenador intensificou os exercícios de percepção corporal e o movimento por meio da interação corporal, como, por exemplo, orientando a realização de um círculo para massagem nas costas uns dos outros simultaneamente. Aqui novamente se perceberam a disponibilidade e os bloqueios socioculturais. Os exercícios ajudaram, assim, a recuperar a autoestima, a desenvolver uma consciência corporal mais ampla, a refletir sobre questões de gênero e valorizações de partes do corpo.

Em um terceiro momento, o coordenador trabalhou com o grupo de participantes a percepção mais atenta do local onde se estava, criando maior familiarização com o ambiente e, ao mesmo tempo, dando continuidade a um processo de despertamento da capacidade de observação e de concentração individual e coletiva. Esses exercícios consistiram em andar pela sala, observar as estruturas (paredes, teto, colunas, as aberturas e acessos das janelas e portas, o piso em suas características e em seu estado), as dimensões (largura, altura, profundidade), as luminosidades, os mobiliários, os objetos, assim como as áreas vazias. Sem nenhum tipo de inter-relação entre os participantes neste momento, o exercício físico proposto podia ser simplesmente andar pela sala e, conforme a curiosidade de cada um, tocar superfícies e objetos para percebê-los melhor. 
Chamou a atenção dos coordenadores a mudança que ocorreu no lidar com o corpo, com o movimento, com o outro e com os espaços, conforme os exercícios foram desenvolvidos. No início, percebeu-se que os participantes tinham reações contidas, riam dos movimentos incomuns, demonstravam vergonha do próprio corpo; no andamento do seminário, se perceberam a capacidade de percepção de si e do outro, a expressão mais lúdica, a interação mais explícita e consciente. Esse desenvolvimento se tornou muito importante para as demais atividades.

\section{2) O corpo, o movimento e a liturgia - a vida na liturgia}

Feitos os exercícios corporais e de experimentação, o segundo momento proposto pelos coordenadores, que pode ser desenvolvido em uma ou mais sessões, foi de reflexão com o grupo sobre os ritos relacionados a uma determinada parte da liturgia do culto. Aqui, especificamente, foi colocado em prática um dos objetivos principais do seminário que é pensar a liturgia e o culto a partir da própria vida, a partir do corpo e da cultura e não a partir do ordo, do conjunto de elementos e formas da tradição.

No primeiro seminário, em 2016, foi trabalhada a liturgia de abertura, mais precisamente a acolhida e a saudação. Refletiu-se sobre ritos e gestos cotidianos que demarcam o início de algo: Como dar início a algo? É possível voltar atrás quando já demos início a algo?

Seguindo a reflexão, foram postos em pauta os ritos de início, como os ritos e gestos que expressam o início de um novo ano, o início da amizade, o início de uma peça no teatro. Quando "inicia o início"? A peça de teatro, por exemplo, inicia, frequentemente, quando se abrem as cortinas ou são acendidas as luzes do palco. E o culto? Quando e como inicia o culto? Quais as dimensões corporais, espaciais, temporais, simbólicas que são mobilizadas pelos ritos iniciais nas liturgias? Em relação ao culto cristão, considera-se que são ritos que marcam o início: a invocação ou saudação trinitária, o sinal sonoro-musical dos sinos ou do prelúdio, o gestual, como a entrada da equipe litúrgica ou a oração silenciosa do ou da presidente da liturgia diante do altar ou da mesa, o gesto comunitário de ficar de pé, o silêncio, a acolhida etc.

Após essa reflexão, a atividade seguinte foi feita em pequenos grupos. Cada grupo deveria expressar um momento de início do culto corporalmente (aproveitando várias descobertas e experimentações do momento anterior) e sem usar palavras. Cada grupo apresentou sua sequência de ações e os demais puderam comentá-las. Em seguida, as diferentes expressões foram organizadas em uma expressão ritual maior. Para finalizar, foi realizada uma avaliação sobre como se poderia incorporar aquelas ações na liturgia do culto nas comunidades participantes do seminário.

Outro rito litúrgico analisado em 2016 foi a Eucaristia a partir dos ritos do cotidiano. Em uma conversa coletiva buscou-se com os participantes termos associados à Eucaristia: unidade e comunhão (unir), comensalidade (comer, beber em conjunto), agradecimento (agradecer), memória (fazer memória, rememorar, lembrar). Em seguida, em grupos menores, se deveria buscar no cotidiano um rito que representasse um dos termos associados à Eucaristia: unidade/comunhão, comensalidade, agradecimento, memória. Usando as experiências corporais realizadas, o rito cotidiano deveria 
ser apresentado por meio de expressão corporal e sem o uso de palavras. Sons podiam ser usados para sublinhar ações e trazer a expressão vocal (embora não verbal).

Após um momento de preparação e experimentação, os grupos criaram pequenas cenas teatrais e as apresentaram aos demais: ida ao mercado e preparo de comida para fazer cachorro-quente (comensalidade); roda de chimarrão ${ }^{45}$ (comunhão e união); gesto de agradecimento do artista após uma apresentação (agradecimento); olhar álbum de fotografias (memória). Percebe-se o quanto o cotidiano e as culturas dos e das participantes foram expressados nessas encenações, o que se pode perceber nas situações, gestos, contextos, elementos e alimentos escolhidos. No momento seguinte, a tarefa era de adaptar os ritos cotidianos, criando um rito litúrgico de Eucaristia. Uma das questões que surgiu nas discussões foi sobre o limite entre rito e cotidiano. A Eucaristia é uma refeição (cotidiano e cultural) e, ao mesmo tempo, é um rito, liturgia (ação representativa).

No seminário de 2018, foi trabalhada a liturgia da palavra, em especial as leituras bíblicas. Também os exercícios corporais e experimentações, envolvendo a fala, a leitura e o discurso, deram subsídios fundamentais. Importante foi também o exercício de perceber diferentes formas de discurso presentes na cultura: discurso político, discurso da mídia (telejornal), discurso de formatura, discurso de funeral, bem como diferentes características sonoras de pregação, como o discurso católico, protestante e pentecostal. Individualmente e em grupo, foram realizadas leituras orais do Salmo 102 e do Evangelho de Marcos 7.24-30, criando "partituras" para as leituras, de forma a demarcar no papel diferentes dinâmicas da fala no texto a ser lido (ritmo, pausas, intensidade, dicção, entre outros aspectos).

3) Reflexão sobre a prática litúrgica ou a participação da comunidade na liturgia.

Cada sessão encerrou com um momento de reflexão e registro do que se fez por parte dos participantes. Algumas constatações feitas oralmente pelos participantes tratavam sobre o quanto se sentiam presos a estruturas culturais fixas, agindo dentro de padrões e o quão difícil foi conseguir sair daquilo que estava estabelecido, considerando a vida social e as celebrações litúrgicas. O grupo observou que foi muito difícil resgatar a essência de um rito, sem romper com o próprio rito. Por outro lado, o grupo constatou a dificuldade de perceber ritos e gestos na normalidade e padronização do cotidiano.

A discussão também deu margem para tratar sobre o papel da tradição litúrgica nos processos de colonização e transplante migratório brasileiros, considerando em que medida a tradição é dinâmica e em que medida é estática. Refletiu-se que toda tradição só tem sentido quando pode ser reavivada.

Em 2016, Cardita deu o exemplo do canto de aleluia, o "aleluiar". No culto, canta-se o aleluia sempre de novo, às vezes, inclusive o mesmo canto e, mesmo assim, o aleluia tem sentido diferente, presente, atual, vivo em cada culto. Essa reflexão levou

45 De origem indígena, chimarrão é um chá típico da região sul do Brasil, preparado em uma cuia e sorvido através de uma bomba, compartilhado entre as pessoas. 
ao tema da inculturação e da pós-colonialidade: a liturgia torna-se viva e tem sentido na vida das pessoas quando ela se incultura, se encarna na vida da comunidade celebrante.

Nas reflexões também surgiram questões sobre o rito e suas funções. Rito tem a ver com repetição e com ritmo. O rito não muda com facilidade. Sua estrutura fixa dá liberdade àqueles e àquelas que dele fazem parte, justamente por aquilo que o rito tem de vida.

Com base em Lecoq, consideraram-se os movimentos corporais com qualidade mecânica, dinâmica e poética, pensando-se no gesto cotidiano, no gesto artístico e no gesto no ritual. Na liturgia, parece muitas vezes remarcado o aspecto mecânico dos ritos, permeado por aspectos dinâmicos (de dinamis), sendo interessante pensar os elementos poéticos, no sentido do elemento sagrado e transcendente que cria nas pessoas a experiência mística, única. Esse elemento seria o que dá ao rito litúrgico seu caráter transcendente. Aqui as funções do culto "expressão, orientação, afirmação, integração" (Cornehl) e "identidade, distância, celebração, festa" (Lange) auxiliaram na reflexão.

\section{Considerações finais}

Em relação ao âmbito prático, vale ressaltar o caráter experimental da proposta: não se tratava de um ensinamento de práticas testadas e estabelecidas, uma "oficina", mas um campo laboratorial de risco. O risco, é preciso ressaltar, faz parte do laboratório, pois toda experimentação, embora pautada em estudos anteriores, é um espaço no qual o fracasso pode existir - e isso não anula o aprendizado. Por isso o presente artigo não corresponde a um roteiro metodológico a ser aplicado simplesmente.

Para a pesquisa, um elemento fundamental só seria delineado no momento do próprio encontro: o grupo de participantes. Embora se pudesse presumir certa composição (o fato de ter sido determinada a Faculdades EST como o local de realização e essa contar com estudantes de graduação e pós-graduação em Teologia (em sua maior parte luterana), as experiências individuais, o entendimento de liturgia, a abertura ao novo, a disponibilidade física e cultural só se tornaram conhecidos ao ser estabelecido um grupo e sua dinâmica própria. Isto é, cada "eu" e sua relação pessoal consigo, com o divino, sua relação com a alteridade humana constituem o grupo e a comunidade.

No geral, os e as participantes avaliaram o seminário nas suas duas edições como muito positivo. Observou-se que o êxito do seminário tem a ver com a disposição e abertura demonstradas pelo grupo, uma vez que esse se constitui como protagonista e ao mesmo tempo "material" em pesquisa.

Dos aspectos avaliados pelo grupo, podem-se sintetizar quatro categorias:

\section{1) A relação da liturgia com a vida, com o cotidiano.}

Os e as participantes perceberam que, no seminário e nas ritualizações criadas, se conseguiu refletir melhor aspectos, elementos, gestos e posturas da vida do dia a dia. Observou-se que, muitas vezes, a liturgia parece algo distante do que acontece na vida, como disse um dos participantes: "Nos cultos, em geral, eu não tenho o sentido do que se faz, nem há relação com aquilo que eu levo a sério na vida" (D.). Outra participante reforça essa ideia, refletindo sobre a distância entre o sagrado e o cotidia- 
no: "É importante refletir sobre os elementos do cotidiano para dentro do 'sagrado'. Quando falamos do cotidiano, estamos mais livres. No rito, mudamos a postura e estamos mais formatados. O seminário proporcionou, através da reflexão sobre os ritos cotidianos, a descoberta de outras formas de fazer a liturgia" (E.).

\section{2) O corpo se expressa e comunica na liturgia.}

Assim como o cotidiano foi importante, também o corpo, o contato com o corpo, o movimento, foram avaliados como uma dimensão a ser considerada na liturgia. Observou-se que geralmente não há uma consciência significativa do corpo na liturgia, notoriamente no âmbito protestante, no qual há grande consideração pela palavra e pelo conteúdo. "Geralmente estamos preocupados com o que se vai falar e não com o corpo" (G). Segundo outro participante, o corpo comunica, o corpo - em especial o corpo do liturgo ou da liturga - convida a algo, e isso deveria ser mais explorado, pois, segundo ele, "geralmente o liturgo não convida com o corpo" (S.).

\section{3) Liturgia é algo que se experimenta.}

Um terceiro aspecto relacionado aos outros dois é a experiência. Um participante falou sobre a importância do silêncio na liturgia: "Observei o quanto temos dificuldade de silenciar em nossas liturgias" (Er.). O seminário criou espaço para experimentar: "Quando a gente experimenta, a gente arrisca a acertar”, disse alguém (I.). Na liturgia, há receio de experimentar, como se a liturgia não fosse um espaço para tal. Uma das participantes disse que no seminário sentiu-se fazendo algo verdadeiro e que, por isso, lhe proporcionou uma experiência de estar presente, algo diferente da sociedade individualista, o que, segundo ela, deu-lhe uma sensação de leveza: "Leveza. Sentir como fazendo algo verdadeiro. Na sociedade individualista as pessoas estão 'ausentes', não estão empenhadas pelo rito".

Um dos participantes percebeu que a experimentação proporcionou uma hermenêutica litúrgica diferente: "Falamos da liturgia a partir do nosso ponto de vista, do ponto de vista da comunidade, não dos ministros e ministras" (Ed.). Esse mesmo participante se pergunta a quem serve a liturgia. A possibilidade de experimentar é a grande contribuição do seminário, porque por meio da experimentação surge a consciência de que não é preciso organizar e celebrar a liturgia sempre do mesmo modo. É mais fácil propor algo, quando se experimentam possibilidades.

4) Dificuldade de levar o que se experimentou no seminário para o culto comunitário.

Mesmo considerando o cotidiano, o corpo e a experiência, alguns e algumas participantes reconheceram que o seminário foi um laboratório, algo fora do comum, e que seria muito difícil levar as experiências ali realizadas para o culto regular, como diz uma das participantes: "Foi muito legal o que vivenciamos no seminário. A experiência com a Eucaristia talvez não pudesse ser levada para uma missa paroquial, mas sim para grupos menores, nas famílias, leitura orante, grupos..." (A.). É importante lembrar que a intenção do seminário não era de dar ou criar modelos a serem 
repetidos, mas de proporcionar experiências e reflexões que pudessem sensibilizar e mobilizar os participantes.

A avaliação feita pelo grupo de participantes corrobora as pretensões do Seminário experimental: ritualidades - pesquisas criativas. O cotidiano, a cultura, o corpo e a experiência são interessantes pontos de partida para a reflexão ritual e litúrgica.

Como assinalado em diferentes partes deste artigo, o Seminário Experimental é um experimento. Ele nasceu de uma inquietação por uma liturgia mais relacionada à vida e à cultura da comunidade que participa no culto. Cada um dos e das integrantes do seminário busca analisar essa questão a partir do seu contexto. No caso da IECLB, o seminário tem um grande potencial para aprofundar a renovação litúrgica da igreja, no sentido de aproximar o culto da vida, propiciando a integração do corpo, do espaço, do cotidiano e da cultura brasileira na experiência do culto cristão.

\section{Referências}

ADAM, Júlio C. Liturgia e performance entre representação e comunidação: um breve relatório. Tear - Liturgia em revista, São Leopoldo, n. 40, p. 3-8, jul. 2013.

. Liturgical Formation, Liberation Theology and Latin American Culture. Studia Liturgica, v. 47, n. 1, p. 1-13, 2017.

. Worship with a Brazilian Face. In: VASCONCELOS WILKEY, Gláucia. Worship and Culture. Grand Rapids; Cambridge: Eerdmans, 2014. p. 239-261.

ALLMEN, J. J. von. O culto cristão: teologia e prática. 2. ed. São Paulo: Aste, 2006.

ARTAUD, Antonin. O teatro e seu duplo. São Paulo: Martins Fontes, 1993.

BARONTO, Luis Eduardo Pinheiro. Laboratório Litúrgico: pela inteireza do ser na vivência ritual. São Paulo: Salesiana, 2000.

BARROS, Marcelo. Celebrar Deus da vida: tradição litúrgica e inculturação. São Paulo: Loyola, 1992. JAGESSAR, Michael; BURNS, Stephen. Christian Worship: Postcolonial Perspectives. London: Cross Cultural Theologies, 2011.

BOSI, Alfredo. Dialética da Colonização. São Paulo: Cia das Letras, 1982. p. 11ss; p. 15; p. 19; p. 26ss.

BROOK, Peter. O teatro e seu espaço. Petrópolis: Vozes, 1970.

BUYST, Ione. Como estudar liturgia: princípios de ciência litúrgica. 2. ed. São Paulo: Paulinas, 1990. BUYST, Ione. Teologia e liturgia na perspectiva da América Latina. In: FAVRETO, C.; RAMPON, Ivanir A. (Orgs). Eu sou o que sou. Passo Fundo: Berthier, 2008. p. 38-76.

CARVAlHAES, Cláudio (Ed.). Liturgy in Postcolonial Perspectives: Only One is Holy. New York: Palgrave Macmillan, 2015.

CONSELHO de liturgia da IECLB. Celebrações do Povo de Deus: Prontuário Litúrgico da IECLB. São Leopoldo: Sinodal, 1991.

CHUPUNGCO, Anscar J. Two Methods of Liturgical Inculturation. In: STAUFFER, S. Anita (Ed.). Christian worship: unity in cultural diversity. Geneva: LWF, 1996. p. 77-94.

CORNEHL, Peter. Theorie des Gottesdienst. Theologie Quartalsschrift, n. 159, p. 178-195, 1979. FRIEDRICH, Marcus A. Liturgische Körper: der Beitrag von Schauspieltheorien und -techniken für die Pastoralästhetik. Stuttgart; Berlin; Köln: Kohlhammer, 2001.

HEIMBROCK, H.-G. Gottesdienst: Spielraum des Lebens. Sozial- und Kulturwissenschaftliche Analysen zum Ritual in praktisch-theologischem Interesse. Kampen: Kok Weinheim: Deutscher Studien Verlag, 1993.

IECLB. Livro de Culto. São Leopoldo: Sinodal, 2003. 
INNES, Christopher. Holy Theatre: Ritual and the Avant Garde. Cambridge University Press, 1981. KIRST, Nelson. Liturgia. In: SCHNEIDER-HARPPRECHT, Christoph (Org.). Teologia prática no contexto da América Latina. São Leopoldo: Sinodal; ASTE, 1998. p. 119-141.

KIRST, Nelson. Renovação litúrgica: experiências recentes na IECLB. Tear-Liturgia em Revista, São Leopoldo, n. 24, p. 5-16, dez. 2007.

LANGE, Ernst. Predigen als Beruf: Aufsätze zu Homiletik, Liturgie und Pfarramt. 2. ed. München: Kaiser, 1987.

LARTEY, Emmanuel. Postcolonializing God: an African Practical Theology. London: SCM, 2013. LATHROP, Gordon. The shape of the liturgy. In: STAUFFER, S. Anita (Ed.). Christian worship: unity in cultural diversity. Geneva: LWF, 1996. p. 67-75.

LECOQ, Jacques. O corpo poético: uma pedagogia da criação teatral. Trad. Marcelo Gomes. São Paulo: SENAC São Paulo; SESC SP, 2010.

MARASCHIN, Jaci. Da leveza e da beleza: liturgia e pós-modernidade. São Paulo: Aste, 2010. p. 25. MEYER-BLANCK, Michael. Inszenierung des Evangeliums. Göttingen: Vandenhoeck \& Ruprecht, 1997.

NIETZSCHE, Friedrich. O Nascimento da Tragédia: ou Helenismo ou Pessimismo. São Paulo: Companhia das Letras, 2007.

PANOTTO, Nicolás. Religión, Política y Poscolonialidad en América Latina: hacia una teología posfundacional de lo público. Madrid; Buenos Aires: Miño y Dávila, 2016.

PLÜSS, David. Gottesdienst als Texinszenierung: Perspektiven einer performativen Ästhetik des Gottesdienstes. Zürich: TVZ, 2007.

ROSENFELD, Anatol. Teatro alemão: história e estudos. I parte - esboço histórico. São Paulo: Brasiliense, 1968.

RÖSSLER, Dietrich. Die Vernunft der Religion. München: Piper, 1976.

SCHEFFLER, Ismael. Carcaterísticas do sagrado nas propostas teatrais de Antonin Artaud e Jerzy Grotowski. 2004. 156 f. Dissertação (Mestrado em Teatro) - Universidade do Estado de Santa Catarina, Programa de Pós-Graduação em Teatro, Florianópolis, 2004.

O Laboratório de Estudo do Movimento e o percurso de formação de Jacques Lecoq.

2013. $591 \mathrm{f}$. Tese (Doutorado em Teatro) - Universidade do Estado de Santa Catarina, Programa de Pós-Graduação em Teatro, Florianópolis, 2013.

SCHILSON, Arno; HAKE, Joachim (Orgs.). Drama "Gottesdienst”: zwischen Inszenierung und Kult. Stuttgart: Kohlhammer, 1998.

SCHLEIERMACHER, Friedrich. Die Praktische Theologie nach den Grundsäzen der Evangelischen Kirche. Berlin: O. Reimer, 1850 (1983).

VANNUCCHI, Aldo. Liturgia e libertação. São Paulo: Loyola, 1982.

WAINWRIGHT, Geoffrey. Fundamentação sistemático-teológica. In: SCHMIDT-LAUBER, H.-C. et al. (Orgs.) Manual de Ciência Litúrgica. São Leopoldo: EST; Sinodal, 2011. v. 1, p. 104-135. WHITE, James F. Introdução ao Culto Cristão. São Leopoldo: Sinodal, 1997. 